\title{
Options for managing infected ascending aortic grafts
}

\author{
Scott A. LeMaire, MD, ${ }^{a}$ and Joseph S. Coselli, MD
}

See related article on page 1051 .

From the Division of Cardiothoracic Surgery, Michael E. DeBakey Department of Surgery, Baylor College of Medicine, ${ }^{\mathrm{a}}$ Houston, Tex; and the Cardiovascular Surgery Service of the Texas Heart Institute at St. Luke's Episcopal Hospital, ${ }^{\text {b }}$ Houston, Tex.

Joseph Coselli, MD, reports consulting fees from Vascutek Terumo and Edwards LifeSciences and grant support from St Jude Medical and Cook, Inc.

Received for publication May 1, 2007; accepted for publication May 14, 2007.

Address for reprints: Scott A. LeMaire, MD, Division of Cardiothoracic Surgery, Michael E. DeBakey Department of Surgery, Baylor College of Medicine, One Baylor Plaza, BCM 390, Houston, TX 77030 (E-mail: slemaire@bcm.edu).

J Thorac Cardiovasc Surg 2007;134:839-43

0022-5223/ $\$ 32.00$

Copyright $(9) 2007$ by The American Association for Thoracic Surgery

doi:10.1016/j.jtcvs.2007.05.059

I nfections involving ascending aortic grafts are extremely difficult to eradicate and are frequently lethal. Successfully treating this complication is always challenging and is especially problematic when the infection extends into adjacent prosthetic material in the aortic root-as in patients with composite valve grafts (CVGs) - or in the aortic arch. Although antibiotics are a critical component of treatment, they are rarely effective as the sole form of therapy. Among the many patients described in reports of ascending aortic graft infection, only a handful have been successfully treated with antibiotics alone. ${ }^{1-4} \mathrm{We}^{1}$ previously reported that of 7 patients with infected ascending/arch grafts in whom nonoperative treatment was attempted, medical treatment ultimately failed in 3 (43\%), necessitating operation. In 1995, Gott and associates ${ }^{4}$ reported that of 7 patients treated nonoperatively for CVG endocarditis, only 2 (29\%) survived. These authors later reported using antibiotics alone to successfully treat 5 patients with Marfan syndrome who had early CVG endocarditis, but the authors emphasized that this treatment approach is not sufficient in patients with severe prosthetic infections. ${ }^{3}$ In their brief communication in this issue, Akowuah and colleagues ${ }^{5}$ describe treating 2 patients with antibiotics alone; both patients died. The dismal results of nonoperative management justify aggressive surgical treatment of infected ascending aortic grafts.

The cornerstone surgical strategy for treating patients with infected peripheral vascular grafts is graft removal and extra-anatomic bypass. Although technically possible, ${ }^{6}$ extra-anatomic bypass is not suitable for managing ascending aortic graft infections; therefore, the surgical options involve either salvaging the existing graft or replacing it in situ. In either case, the need to leave prosthetic material in an infected surgical field makes it difficult to eradicate the infection. In 1984, Hargrove and Edmunds ${ }^{7}$ introduced guidelines to address this problem, emphasizing the need for prompt and thorough surgical debridement, antiseptic irrigation, and appropriate antibiotic therapy. Notably, these early recommendations-which were based on the authors' pioneering experience with only 4 patients-remain the central guiding principles for treating patients with infected thoracic aortic grafts today. ${ }^{5}$

Beyond these well-established principles of debridement and antimicrobial treatment, the options for dealing with an infected ascending aortic graft are characterized by the two main areas of controversy: whether to remove the infected graft and, if it is removed, what to replace it with. Although evidence-based practice guidelines are becoming available for many issues cardiothoracic surgeons face, ${ }^{8}$ it is unlikely that such guidelines will ever be established for managing this challenging problem. The literature on surgical treatment of ascending aortic graft infection fails to provide even the lowest level of evidence (level C, consensus expert opinion) on which to base a concrete recommendation. Although plenty of expert opinion is available, consensus is clearly lacking. The accumulated expert opinion, however, comprises a valuable armamentarium that surgeons can use when planning treatment for their patients. In their report, Akowuah and colleagues ${ }^{5}$ illustrate the value of using individualized treatment strategies in different clinical situations; this provides a welcome opportunity to review the available options.

\section{Graft Removal and Replacement With a Synthetic Graft}

Infected ascending aortic grafts have often been replaced with new synthetic grafts, especially during the era before bioprosthetic alternatives became commercially available. In cases in which the extent of replacement has been relatively limited, outcomes have generally been very good. In 1990, we ${ }^{1}$ reported using new Dacron 
tube grafts or patches to treat postoperative aortic infections in 10 patients; there were no early deaths, 1 late death, and no cases of recurrent infection. Along with other groups that have used synthetic grafts to replace infected ascending aortic grafts, we have emphasized the value of thorough debridement and other measures to reduce the chance of recurrent infection, including postoperative mediastinal irrigation with an antibacterial solution and coverage of the graft with viable tissue pedicles. ${ }^{7,9-11}$

Completely removing infected prosthetic material and replacing it with a new graft is particularly challenging when the infection involves a CVG. Combining root rereplacement with aggressive debridement in an inflamed and necrotic field often results in prolonged operations with substantial blood loss. Given the technical challenges of this procedure and the poor condition of many of these patients, it is not surprising that these operations have been associated with poor outcomes. In our cumulative experience, 5 of the 11 patients with infections who had new CVGs placed died within 30 days (46\%). ${ }^{1,12}$ Other groups have reported similarly disappointing results when new CVGs were used to replace infected CVGs. ${ }^{4,13}$

A few groups, however, have achieved very satisfying results using this approach to treat CVG infection. RalphEdwards, David, and Bos ${ }^{14}$ reported excellent early survival $(10 / 11,91 \%)$ in patients in whom CVGs were used to replace infected grafts. This series was noteworthy for the authors' use of extensive debridement that often required reconstruction of the left ventricular outflow tract with glutaraldehyde-fixed bovine pericardium and lengthening of the coronary arteries with saphenous vein or synthetic grafts. However, in a subsequent report, ${ }^{15}$ the authors noted a $25 \%$ incidence of recurrent prosthetic valve endocarditis in their series; this group currently uses homograft roots whenever available. Hagl and colleagues ${ }^{16}$ have also reported excellent early survival in 23 patients treated with aggressive debridement and replacement with new CVGs; moreover, all but 1 patient in the series remained free of recurrent endocarditis during follow-up. Because of these results, the Mount Sinai group continues to use CVGs in this setting, except in patients with contraindications to anticoagulation, who are better served by having the infected CVG replaced with a homograft.

\section{Graft Removal and Replacement With a Tissue Graft}

Several groups currently favor replacing infected ascending aortic prostheses with cryopreserved aortic homografts. ${ }^{2,3,17-19}$ Although homografts are not impervious to endocarditis, ${ }^{19-21}$ they appear to be more resistant to infection than synthetic grafts, perhaps because homografts allow better antibiotic penetration and inherently attract immune cells. ${ }^{17}$ Retrospective data have suggested that, compared with using synthetic grafts, using cryopreserved homografts for treating vascular infec- tions is associated with improved outcomes, including better elimination of infection, fewer postoperative complications, and longer disease-related survival. ${ }^{22}$ The malleability of the homograft tissue is considered a technical advantage because it enables the graft to conform to a widely debrided annulus. ${ }^{18}$ In situ replacement of contaminated or infected grafts in the aortic root, ascending aorta, and transverse aortic arch has been associated with encouraging early and midterm results; although available reports only describe small groups of patients, these patients' collective early survival exceeds $90 \%$. $^{2,3,15,18,23-25}$

One commonly cited disadvantage of using homografts is their predisposition to progressive deterioration and ultimate need for rereplacement. ${ }^{16,19}$ Another limitation is the relatively low tensile strength of the homograft tissue; because of this, it is extremely important to avoid anastomotic tension caused by using an inappropriately short graft. Unfortunately, in many cases, a single homograft will not reach the distal ascending aorta or transverse arch. ${ }^{18}$ Gaps between the distal end of the homograft and the native aorta can be bridged with a segment of synthetic graft, but this essentially defeats one of the purposes of selecting a tissue graft in the first place. Extensive aortic replacement can be accomplished by using total arch homografts, but these are rarely available. ${ }^{23}$ To address this problem, Lytle and colleagues ${ }^{18}$ have described using 2 standard aortic root homografts to perform hemiarch replacement; reversing the distal homograft after its valve has been removed allows the larger proximal end to be used for the arch anastomosis.

Although tissue replacement of infected CVGs has traditionally required the use of homografts, porcine xenograft roots have emerged as another option for replacing the infected root. Akowuah and colleagues ${ }^{5}$ successfully treated 1 of their patients by using a xenograft root. These grafts have the advantage of on-the-shelf availability and have been particularly useful in areas of the world where homografts are difficult or impossible to obtain. ${ }^{26,27}$ Compared with homografts, xenografts appear to be less susceptible to progressive degeneration. Mohammadi and colleagues ${ }^{28}$ recently described outstanding freedom from structural valve deterioration in a large series of patients who received porcine xenografts. Valve dysfunction developed in only 1 of 133 patients who had porcine xenograft root implantations. This problem was due to a leaflet tear and required reoperation 12 years after the initial implantation. Porcine xenograft endocarditis is also rare ${ }^{28}$; although these grafts have a synthetic sewing cuff, their treatment with glutaraldehyde may confer resistance to infection.

Porcine xenografts, however, are even shorter than most homograft roots; therefore, an additional segment of graft is generally required to bridge the gap between the distal end of the xenograft and the patient's aorta. As described above, this can be accomplished with a segment of synthetic graft or the tubular portion of a homograft. Additionally, stentless 
TABLE 1. Reports describing surgical treatment to salvage infected ascending aortic grafts

\begin{tabular}{|c|c|c|}
\hline Author and year & No. of patients & Early survivors \\
\hline Hargrove and Edmunds, $1984^{7}$ & 1 & 1 \\
\hline Seguin and Loisance, $1985^{29}$ & 2 & 2 \\
\hline Coselli et al, $1990^{1}$ & 16 & 14 \\
\hline Krabatsch and Hetzer, $1995^{30}$ & 1 & 1 \\
\hline Chavanon et al, $1998^{31}$ & 1 & 1 \\
\hline Nakajima et al, $1999^{13}$ & 4 & 3 \\
\hline Coselli et al, $1999^{2}$ & 3 & 2 \\
\hline Mathes et al, $2000^{33}$ & 1 & 1 \\
\hline Luciani et al, $2001^{32}$ & 1 & 1 \\
\hline Kawachi et al, $2002^{34}$ & 1 & 1 \\
\hline LeMaire et al, $2002^{12}$ & 1 & 1 \\
\hline Mitra et al, $2005^{35}$ & 9 & 9 \\
\hline Akowuah et al, $2007^{5}$ & 5 & 5 \\
\hline Total & 46 & $42(91 \%)$ \\
\hline
\end{tabular}

xenograft roots are not recommended for use in cases that require extensive annular debridement; the irregular base for the proximal suture line can cause significant distortion of the valve and produce regurgitation. ${ }^{16}$

\section{Salvaging the Original Graft}

Regardless of the type of conduit used, removing and replacing an infected ascending aortic graft is a major undertaking that carries substantial risk of morbidity and mortality. The alternative surgical approach that Akowuah and colleagues $^{5}$ highlight-extensive mediastinal debridement and irrigation- has been used successfully by many groups (Table 1). ${ }^{1,2,7,12,13,29-35}$ All of their reports include patients with ascending aortic grafts, many of whom also received an arch graft, CVG, or separate aortic valve prosthesis. These patients' collective early survival is $91 \%$. Nearly all of the reports include follow-up of at least 2 years, and most specifically document the absence of recurrent graft infection after the definitive procedure.

The techniques used to achieve these encouraging results share several common features but also vary substantially. Most reports emphasize the need for thorough debridement of all surrounding infected and necrotic material as well as intraoperative irrigation with povidone-iodine or antibiotic solution. Catheters are occasionally left in the mediastinum to facilitate postoperative irrigation. ${ }^{30,32,33}$ The technique described by Kawachi and colleagues ${ }^{34}$ is unique in that they used fibrin glue containing gentamicin to fill dead space. Most groups covered the graft with a vascular tissue flap; omentum was the most common flap, although muscle flaps were also frequently used. Tissue coverage was often performed immediately after mediastinal debridement and irrigation; however, several authors used staged procedures, performing debridement during the first operation and tissue coverage and definitive wound closure during the second operation. ${ }^{33-35}$ In a few cases of staged treatment, the sternal wound was left open to facilitate a period of mediastinal packing and frequent dressing changes before the second operation was performed. ${ }^{7,13}$

Several factors have been discussed in the context of selecting patients who are likely to benefit from graftsparing procedures. This approach is particularly wellsuited for patients with poor physiologic reserve, who are unlikely to tolerate graft removal. ${ }^{32}$ Akowuah and colleagues $^{5}$ reserved this approach for patients with grafts contaminated from adjacent sternal wound infections; although graft-sparing operations seem ideal for this type of patient, we and other groups have applied this approach without using sternal wound infection as a criterion. ${ }^{1,13,35}$ The severity of graft involvement is another aspect to consider. In a case reported by Hargrove and Edmunds, ${ }^{7}$ the decision not to remove the graft was based largely on the fact that the "suture lines were completely covered with healthy autogenous tissue." Although intact grafts with unexposed suture lines are desirable, we and other authors have used this approach in selected patients with contaminated anastomoses, including those with anastomotic leaks, pseudoaneurysms, and aortocutaneous fistulas. ${ }^{1,2,12,29,34}$ In most cases, the culprit anastomotic defects were treated by primary repair. Kawachi and colleagues ${ }^{34}$ used Dacron patches to repair suture line dehiscence at the distal anastomosis. $\mathrm{We}^{1}$ have avoided leaving the graft in place in patients with antibiotic-resistant infections (indicted by persistent positive blood cultures), severe graft deformity, prosthetic valve vegetations, or adjacent diseased aortic segments that needed replacement (because of severe aortic valve regurgitation, large aneurysm, or aortocardiac fistula, for example).

\section{Strategies to Prevent Recurrent Infection}

Irrespective of how the infected graft is specifically dealt with, several strategies are commonly used to prevent recurrent infection. Irrigation with antiseptic solutions-principally povidone-iodine or antibiotics-is a ubiquitous component of treatment, although the mode of delivery has varied. At a minimum, the aortic graft and surrounding mediastinal tissues are thoroughly irrigated during the operation. Mediastinal catheters are commonly placed to enable postoperative irrigation. ${ }^{32}$ Finally, if the sternum is left open after the debridement procedure, the mediastinum can be packed with sponges soaked in povidone-iodine. ${ }^{13}$ When povidone-iodine is used for postoperative irrigation, care is taken to avoid iodine toxicity and resulting hepatic dysfunction. Precautions include using dilute solutions (eg, 1\% povidone-iodine) for irrigation while monitoring daily serum iodine concentrations (normal range, 4 to 8 $\mathrm{mg} / \mathrm{dL}$ ) and liver enzyme levels. ${ }^{13,32,33}$

Other methods of delivering local antibiotics may also be useful. Some authors have used gentamicin-impregnated 
fibrin glue to seal anastomoses and fill dead space. ${ }^{24,34}$ When using synthetic grafts for replacement, we routinely soak gelatin-sealed Dacron grafts in rifampin before implantation; although this practice has not been adequately studied in the setting of thoracic aortic reconstructions, encouraging results have been reported in the peripheral vascular surgery literature. ${ }^{36,37}$ The development of effective, commercially available antibiotic-bonded grafts would be useful for these cases.

It may also be helpful to avoid using suture and reinforcement materials that are likely to harbor bacteria. When working in a contaminated field, we favor using monofilament suture instead of braided suture. We also avoid synthetic materials when buttressing anastomoses and cannulation sites; pledgets and reinforcing strips can be made from excess homograft tissue, autologous pericardium, or glutaraldehydetreated bovine pericardium instead of Teflon felt. ${ }^{22}$

Most reports describe using viable tissue to obliterate dead space and provide vascularized coverage of the graft. Occasionally, this can be accomplished by mobilizing local tissues, such as the thymus and pericardial fat pads. ${ }^{1}$ More commonly, coverage is achieved with a pedicled omental or muscle flap. Omentum is particularly popular because, in patients who have not had previous abdominal surgery, omentum can be easily accessed by extending the sternotomy incision into the abdomen for a short distance. ${ }^{7,9,11-13,25,29,30,32,33}$ The blood supply to the omentum is preserved by basing the pedicle on the right gastroepiploic artery. In addition to filling dead space, the vascularized omental pedicle improves oxygen supply to the region, enhances immunologic response, increases antibiotic delivery, and absorbs wound secretions that can serve as substrates for bacterial growth. ${ }^{9,29,32}$ Muscle flaps used in patients with ascending aortic graft infection have included pectoralis major, rectus abdominis, latissimus dorsi, and serratus anterior. ${ }^{1,7,13,31,33,35}$ Occasionally, a combination of flaps is necessary to achieve adequate coverage. The aortic graft can be covered with a vascularized flap during the original debridement/graft replacement procedure or in a delayed manner after a period of closed mediastinal irrigation or open wound care.

The final aspect of preventing recurrent graft infection is administering systemic antibiotics. In most cases, a period of intravenous antibiotic administration is followed by long-term oral antibiotic therapy. Choices regarding the length of antibiotic treatment remain arbitrary, and the efficacy of long-term antibiotics remains unproven. ${ }^{7}$ Approaches to antibiotic treatment have ranged from a 7-day course of intravenous antibiotics without subsequent oral therapy ${ }^{34}$ to lifelong antibiotic treatment. ${ }^{1,7,33}$ Although we continue to advocate lifelong suppressive antibiotic therapy-especially in patients with residual synthetic graft material - there is admittedly no evidence supporting this practice. ${ }^{12}$ It certainly seems reasonable to limit the length of antibiotic treatment in patients whose infected grafts have been replaced with homografts. In many reported cases, the approach to antibiotic treatment was individualized according to multiple clinical factors, including severity of infection, comorbid conditions, the specific pathogens involved, and the postoperative course. Hagl and colleagues ${ }^{16}$ recommend a strategy that is based on operative findings: if surgical cultures are positive, patients would receive at least 6 weeks of antibiotic therapy; if the cultures are negative but organisms are seen on Gram stain, patients would receive at least 4 weeks of antibiotic treatment; and if cultures and Gram stain are negative, antibiotic treatment would be continued for only 2 weeks.

\section{Preventing Graft Infection}

Because of the dire consequences of thoracic aortic graft infection, we maintain an aggressive approach to prophylaxis in all patients undergoing thoracic aortic repairs, despite the absence of supportive evidence. Specifically, we routinely apply topical cephalosporin or vancomycin powder to the graft and continue intravenous antibiotics postoperatively until all chest drains and central venous lines are removed. It is important to recognize that the threat of aortic graft infection persists long after hospital discharge. One unusual aspect of Akowuah and colleagues' series $^{5}$ is the short interval between the initial operation and the graft infection (range 6-30 days). Many other series have demonstrated that the risk of aortic graft infection continues for years after the initial operation. ${ }^{1,2,7,12,14,16}$ We believe that this risk justifies an aggressive approach to antibiotic prophylaxis whenever patients with aortic grafts require invasive procedures that produce bacteremia, such as bronchoscopy, colonoscopy, and dental procedures, regardless of the length of time since the graft was implanted; we favor periprocedural intravenous broad-spectrum antibiotics over oral antibiotic prophylaxis in these patients. Experimental models are desperately needed to improve strategies for short- and long-term prevention of thoracic aortic graft infection. ${ }^{38}$

\section{Conclusions}

It is notable how little evidence is available to guide surgeons in treating patients with ascending aortic graft infection. There are, however, many established options for managing the infected graft, all of which have their place within the surgical armamentarium. In situ replacement can be effective but is often associated with substantial morbidity and mortality, especially in patients with infected CVGs. In many cases, existing grafts can be salvaged through a regimen of aggressive debridement, irrigation, and coverage with healthy tissue. Ultimately, the treatment strategy should be selected on the basis of relevant clinical factors and tailored specifically to the individual patient. 
We thank Stephen N. Palmer, PhD, ELS, for providing editorial assistance.

\section{References}

1. Coselli JS, Crawford ES, Williams TW Jr, Bradshaw MW, Wiemer DR, Harris RL, et al. Treatment of postoperative infection of ascending aorta and transverse aortic arch, including use of viable omentum and muscle flaps. Ann Thorac Surg. 1990;50:868-81.

2. Coselli JS, Köksoy C, LeMaire SA. Management of thoracic aortic graft infections. Ann Thorac Surg. 1999;67:1990-3.

3. Gott VL, Cameron DE, Alejo DE, Greene PS, Shake JG, Caparrelli DJ, et al. Aortic root replacement in 271 Marfan patients: a 24-year experience. Ann Thorac Surg. 2002;73:438-43.

4. Gott VL, Gillinov AM, Pyeritz RE, Cameron DE, Reitz BA, Greene PS, et al. Aortic root replacement: risk factor analysis of a seventeenyear experience with 270 patients. J Thorac Cardiovasc Surg. 1995; 109:536-44.

5. Akowuah E, Narayan P Jr, Angelini G, Bryan AJ. Management of prosthetic graft infection after surgery of the thoracic aorta: removal of the prosthetic graft is not necessary. J Thorac Cardiovasc Surg. 2007;134:1051-2.

6. Bove EL, Parker FB Jr, Marvasti MA, Randall PA. Complete extraanatomic bypass of the aortic root: treatment of recurrent mediastinal infection. J Thorac Cardiovasc Surg. 1983;86:932-4.

7. Hargrove WC III, Edmunds LH Jr. Management of infected thoracic aortic prosthetic grafts. Ann Thorac Surg. 1984;37:72-7.

8. Edwards FH, Engelman RM, Houck P, Shahian DM, Bridges CR. The Society of Thoracic Surgeons practice guideline series: antibiotic prophylaxis in cardiac surgery, part I: duration. Ann Thorac Surg. 2006;81:397404.

9. Miller DW Jr, Johnson DD. Omental pedicle graft in the management of infected ascending aortic prostheses. Ann Thorac Surg. 1987;44: 614-7.

10. Soyer R, Bessou JP, Bouchart F, Redonnet M, Mouton-Schleifer D, Arrignon J. Surgical treatment of infected composite graft after replacement of ascending aorta. Ann Thorac Surg. 1994;58:425-8.

11. Takano T, Fukaya Y, Nakano H, Kuroda H, Amano J. Combined therapies for composite graft infection after Bentall's procedure. Ann Thorac Surg. 1998;66:564-6.

12. LeMaire SA, DiBardino DJ, Köksoy C, Coselli JS. Proximal aortic reoperations in patients with composite valve grafts. Ann Thorac Surg. 2002;74:S1777-80.

13. Nakajima N, Masuda M, Ichinose M, Ando M. A new method for the treatment of graft infection in the thoracic aorta: in situ preservation. Ann Thorac Surg. 1999;67:1994-6.

14. Ralph-Edwards A, David TE, Bos J. Infective endocarditis in patients who had replacement of the aortic root. Ann Thorac Surg. 1994;58: 429-32.

15. Raanani E, David TE, Dellgren G, Armstrong S, Ivanov J, Feindel CM. Redo aortic root replacement: experience with 31 patients. Ann Thorac Surg. 2001;71:1460-3.

16. Hagl C, Galla JD, Lansman SL, Fink D, Bodian CA, Spielvogel D, et al. Replacing the ascending aorta and aortic valve for acute prosthetic valve endocarditis: is using prosthetic material contraindicated? Ann Thorac Surg. 2002;74:S1781-5.

17. Vogt PR, Brunner-LaRocca HP, Lachat M, Ruef C, Turina MI. Technical details with the use of cryopreserved arterial allografts for aortic infection: influence on early and midterm mortality. J Vasc Surg. 2002;35:80-6.

18. Lytle BW, Sabik JF, Blackstone EH, Svensson LG, Pettersson GB, Cosgrove DM III. Reoperative cryopreserved root and ascending aorta replacement for acute aortic prosthetic valve endocarditis. Ann Thorac Surg. 2002;74:S1754-7.

19. Kaya A, Schepens MA, Morshuis WJ, Heijmen RH, Brutel de la Riviere A, Dossche KM. Valve-related events after aortic root replace- ment with cryopreserved aortic homografts. Ann Thorac Surg. 2005;79:1491-5.

20. Cattaneo SM, Bethea BT, Alejo DE, Spevak PJ, Clauss SB, Dietz HC, et al. Surgery for aortic root aneurysm in children: a 21-year experience in 50 patients. Ann Thorac Surg. 2004;77:168-76.

21. Yamada A, Okada K, Takahashi R, Okita Y. Pathologic features of cryopreserved aortic allograft implanted in the active infection. $J$ Thorac Cardiovasc Surg. 2006;132:203-4.

22. Vogt PR, Brunner-La Rocca HP, Carrel T, von Segesser LK, Ruef C, Debatin J, et al. Cryopreserved arterial allografts in the treatment of major vascular infection: a comparison with conventional surgical techniques. J Thorac Cardiovasc Surg. 1998;116:965-72.

23. Abad C, Hurle A, Feijoo J, Gomez-Marrero J, Abdallah A. Total aortic arch replacement by a cryopreserved aortic homograft. Eur J Cardiothorac Surg. 1995;9:531-3.

24. Vogt PR, Turina MI. Management of infected aortic grafts: development of less invasive surgery using cryopreserved homografts. Ann Thorac Surg. 1999;67:1986-9.

25. Kato M, Imanaka K, Kyo S, Ohuchi H, Asano H, Takamoto S. Successful treatment of ascending aortic graft infection after operation for acute aortic dissection with peripheral malperfusion. Ann Thorac Surg. 2004;77:2194-5.

26. Fukui T, Suehiro S, Shibata T, Hattori K, Hirai H, Aoyama T. Aortic root replacement with Freestyle stentless valve for complex aortic root infection. J Thorac Cardiovasc Surg. 2003;125:200-3.

27. Murayama H, Asano S, Yanai M, Yamamoto M, Tatsuno K. Reoperation for composite graft infection after aortic root replacement. Jpn J Thorac Cardiovasc Surg. 2005;53:490-3.

28. Mohammadi S, Baillot R, Voisine P, Mathieu P, Dagenais F. Structural deterioration of the Freestyle aortic valve: mode of presentation and mechanisms. J Thorac Cardiovasc Surg. 2006;132:401-6.

29. Seguin JR, Loisance DY. Omental transposition for closure of median sternotomy following severe mediastinal and vascular infection. Chest. 1985;88:684-6.

30. Krabatsch T, Hetzer R. Infected ascending aortic prosthesis: successful treatment by thoracic transposition of the greater omentum. Eur J Cardiothorac Surg. 1995;9:223-5.

31. Chavanon O, Thony F, Lebeau J, Blin D. Exposed prosthesis of a complex reconstruction of the ascending aorta and aortic arch in a sternal wound infection: successful treatment by a pectoral muscle flap. Eur J Cardiothorac Surg. 1998;13:98-100.

32. Luciani N, Lapenna E, De Bonis M, Possati GF. Mediastinitis following graft replacement of the ascending aorta: conservative approach by omental transposition. Eur J Cardiothorac Surg. 2001;20:418-20.

33. Mathes DW, Yaremchuk MJ, Isselbacher EM, Madsen JC. Successful in situ treatment of an infected ascending aortic graft. Ann Thorac Surg. 2000;70:1410-2.

34. Kawachi Y, Nakashima A, Onzuka T, Yamauchi T. False aneurysm of the ascending aorta concomitant with chronic mediastinitis after tube graft replacement in octogenarian. Eur J Cardiothorac Surg. 2002;22: 450-3.

35. Mitra A, Spears J, Perrotta V, McClurkin J, Mitra A. Salvage of infected prosthetic grafts of the great vessels via muscle flap reconstruction. Chest. 2005;128:1040-3.

36. Bandyk DF, Novotney ML, Johnson BL, Back MR, Roth SR. Use of rifampin-soaked gelatin-sealed polyester grafts for in situ treatment of primary aortic and vascular prosthetic infections. J Surg Res. 2001; 95:44-9.

37. Young RM, Cherry KJ Jr, Davis PM, Gloviczki P, Bower TC, Panneton JM, et al. The results of in situ prosthetic replacement for infected aortic grafts. Am J Surg. 1999;178:136-40.

38. Rowe NM, Impellizzeri P, Vaynblat M, Lawson NM, Kim YD, Sierra $M$, et al. Studies in thoracic aortic graft infections: the development of a porcine model and a comparison of collagen-impregnated Dacron grafts and cryopreserved allografts. J Thorac Cardiovasc Surg. 1999; 118:857-65. 